\title{
Measuring the Quality and Impact of Scientific Information. Scientometry Research Using the Web of Science in the Field of Ethics in Medical Recovery
}

\author{
Angela Repanovici, ${ }^{1}$ Andra Manuela Botez, ${ }^{1}$ Marius Stoianovici, ${ }^{1}$ \\ Nadinne Roman ${ }^{2}$ \\ ${ }^{1}$ Product Design, Mechatronics and Environment Department, Transilvania University of Brasov \\ arepanovici@unitbv.ro, andra.manu@unitbv.ro, marius.stoianovici@unitbv.ro \\ ${ }^{2}$ Faculty of Medicine, Transilvania University of Brasov, nadinneroman@unitbv.ro
}

\begin{abstract}
The study of communication processes in science, the assessment of excellence in research, and quality of research are all issues which pose rising interests to governments, research institutions, universities and financing bodies as a method for assessing the responsibility and the quality of the scientific research. Scientometric performance indicators play an important role in evaluating the scientific production of a country which is why international measurement tools have been developed. This article presents the most frequently-used performance indicators, the benefits of scientometry for academics, and the means to perform a research using the Web of Science database.
\end{abstract}

\section{Keywords}

Scientometric analyse; impact factor; Web of Science; Sci2Toll; ethics; medical recovery.

This is an Open Access article distributed in accordance with the Creative Commons Attribution Non Commercial (CC-BYNC-ND 4.0) license, which permits others to copy or share the article, provided original work is properly cited and that this is not done for commercial purposes. Users may not remix, transform, or build upon the material and may not distribute the modified material (http://creativecommons.org/licenses/by-nc/4.0/)

DOI: $10.22618 /$ TP.PCMS.20164.349006 


\section{Introduction}

The famous Thomson Scientific database, established under the name of ISI (the Institute for Scientific Information), has its origins in a bibliography produced and published by Eugene Garfield (the founder of the Institute for Scientific Information) in the early 1960s. The Garfield's original purpose of the researcher was to create a list of the most important scientific journals for researchers and then to measure, evaluate and compare those periodicals.

Garfield discovered the relevance of citations after the two draft documentaries for' 'The Army Medical Library of the USA,"1 where he conducted the "Current List of Medical' 'The Army Medical Library of the USA" Literature" bibliography and then the' "Genetics Citation Index." The latter bibliography inspired Garfield to compile the "Science Citation Index". Since the early 1950s, Eugene Garfield started his work in retrieving the most relevant publications and scientific serials. This work resulted in the publication of two bibliographies from which the famous "impact factor" was to develop: "Current Contents" and "Science Citation Index."

Garfield felt the need for a different way to index scientific literature; if by then the focus was on indexing issues that were often affected by obsolescence; the new vision was that of indexing citations. In his mind, such an index of citations could become in time a unique starting point in documentation and an indispensable tool for scientific research. In addition, citation analysis was, at the time, seen as a way to manage the explosion of publications in terms of information and documentation. Garfield's idea was revolutionary; he not only used the first computer to compile the index, but he saw the quantification of citations as a method for measuring impact in the scientific environment.

Before Garfield, other researchers had used the method of citation analysis in search of a formula to prioritize scientific serial publications. P.L.K. Gross and E. M. Gross ${ }^{2}$ aspired to create a method for selecting journals in chemistry which libraries would find most useful. Thus in 1927, the two conducted a study of citations simply by counting references from the 'Journal of the American Chemical Society' and ordering the journals on the total number of citations obtained. This method was heavily criticized by Estelle Brodman in an article from 1944 . Her critique enumerated two assumptions on the part of the researchers': the first assumption was that a periodical's value is directly proportional to the number of times it is cited, the second assumption is that the journal(s) of the starting citation analysis are representative of an entire domain, and the final assumption is that if the analysis of citations is used more often than a periodical, they can be considered just as valuable. For the first assumption, Brodmann asked specialists in the field to make a list of scientific serials considered to be valuable and compared it to the results obtained from the analysis of Gross and Gross. To mitigate the second assumption, she applied the method of the two researchers using several scientific journals as the basis for quantifying citations and proved that no periodical can be considered to be equal in importance with another in the same specialty.

One possible method for using citation analysis was proposed by Garfield in "ISI impact factor" to be a system which measures the impact a magazine has in the scientific field. The system quantified the number of citations received by each journal included in the "Science Citation Index" for a period of two years in reference to the number of articles published in the most recent two years by the magazine; this resulted in a value in which the periodicals could be ordered. Using this citation analysis, the method of calculating the impact factor allowed for a comparison between magazines regardless of how many articles they have published, the frequency of these publications or their history of publication.

\footnotetext{
${ }^{1}$ Larkey, Sanford V, The Army Medical Library Research Project at the Welch Medical Library, Bull Med Libr. Assoc. 1949 April; 37(2): 121-124.

${ }^{2}$ P. L. K. Gross and E. M. Gross, "College Libraries and Chemical Education." Science 66 (1927): $385-389$. 150. Ref. 149. p. 386. If I Ref. 149. p. 387.

${ }^{3}$ Brodman E. "Choosing Physiology Journals" Bulletin Medical Library Association 32 (1944): 479-483.
} 
Subsequently, citation analysis has become the basic instrument of bibliometry. In past decades, it has been a key element in the development of more complex bibliometric analysis, such as: co-citation analysis, mapping, scientific literature, bibliographic correlation and inter-networking word analysis.

The formula for calculating the impact factor was just one of Garfield's innovations, but it could be applied only to a small group of scientific journals. Therefore, one of the biggest challenges was selecting journals to be included in the three indices. Garfield's desire was to cover all areas of science, which is why the bibliographies were delineated into three categories: exact sciences, social sciences, arts and human sciences. The first edition of the 'Science Citation Index' was published in 1964 in a total of five volumes comprising of 613 journals and 1.4 million bibliographic references. In 1976 the first volume dedicated social science literature appeared: the 'Social Science Citation Index'. In 1979, the bibliography dedicated to human sciences appeared: the 'Arts \& Humanities Citation Index'. Each bibliography was available on tape shortly after the printed edition; they were then be formed into a database: 'Science Citation Index', 'Social Science Citation Index' and 'Arts \& Humanities Citation Index.'

The three bibliographies, accompanied by the ISI impact factor calculated for the included periodicals, have quickly become a working tool for researchers, especially in assessing a researcher's scientific production. The success of the impact factor resounded in the scientific world. It became so important that it came to control editorial science environment and researchers and academics came to be assessed according to the number of articles published in journals with a high impact factor.

In 2008, Thomson Corporation acquired Reuters becoming Thomson Reuters, and the former ISI databases are now part of the Thomson Intellectual Property \& Science division. Eugene Garfield continued his work uninterrupted at the head of the former Institute for Scientific Information as founder and chairman emeritus, continuously contributing to the development of bibliometric database indicators.

\section{Thomson Scientific databases (ISI)}

Bibliographies such as the 'Science Citation Index,' 'Social Science Citation Index" and Arts \& Humanities Citation Index' were available on microfilm shortly after publication and then later converted into a database. These were the first three databases carried out by the 'Institute for Scientific Information', but over time, around thirty scientific databases have been subsequently added. A journal's inclusion in the Thomson ISI databases has become a criterion for evaluating both the magazines as well as the authors of scientific literature, which is why Thomson Reuters provides (for free and online) the list of all publications included in the 'Thomson Scientific' scientific databases,' integrated into a search engine called the Master Journal List. ${ }^{4}$

'Journal Citation Reports' is the only database that contains scientific serial publications rated in the ISI system allowing for more complex bibliometric statistics and advance analysis using the ISI impact factor or other bibliometric indicators that have a similar data set and analysis. It consists of two editions: 'Journal Citation Reports Science Edition' and 'Journal Citation Reports Social Sciences Edition.'

\section{A. Indexing publications in "Thomson Scientific", (ISI)}

The inclusion of a scientific serial publication in 'Thomson Scientific' databases and obtaining a higher impact factor is a goal for every scientific editor aware of the implications of such acceptance today.

The inclusion of a publication in the 'Thomson Scientific' database is the equivalent of international recognition of the scientific quality for that specific publication; it provides an opportunity for international readership and, most often, increases the competition between authors for inclusion in the editorial of the newspaper, which implicitly leads to increasing the quality of the publication.

\footnotetext{
${ }^{4}$ http://ip-science.thomsonreuters.com/mjl/\#scope_notes.
} 


\section{B. ISI impact factor calculation}

After a scientific serial publication is included in the 'Thomson Scientific' (ISI) database, the process of monitoring citations begins. After two years, the impact factor is calculated for the first time; this is the number which will serve as the annual point of reference. The formula for calculating the impact factor is as follows:

Impact factor $=$

The number of citations obtained in last 2 years

The number of articles published in the last 2 years

In the first part of each calendar year, the impact factor for the previous year is calculated. For example, the impact factor for 2013 was published in early 2014, taking into account published articles and citations obtained in 2011 and 2012. Because the impact factor and the other bibliometric indicators are recalculated annually, 'Journal Citation Reports' is available in separate editions for each year individually; the newest edition indicates the calendar year preceding the previous year. In addition, in the first part of the year edition two years older than the calendar year is available. Thus, in early 2014, the 2012 edition was available and in the course of the year the 2013 edition would appear later.

\section{The influence of the impact factor in the scientific world}

Over time, impact factor has become particularly important, even exerting control over the scientific editorial environment. Many universities and other scientific institutions today view a journal's impact factor in the role of qualitative indicator, so researchers or educators are evaluated in terms of the number of articles published in journals with a high impact factor. All of these criteria are used to obtain evidence of academic or research grants.

Stunned by the extent his own impact factor measuring instrument has gained, Eugene Garfield said: "I never could have foreseen the fact that people could transform this into an instrument of evaluation for grants and funding." 5

The reason this tool for measuring the impact of scientific journals enjoyed so much success is because it is an objective method of quantitative measuring that can serve multiple purposes and multiple beneficiaries: from libraries to researchers or academics, to publishers and managers of government agencies.

For researchers, academic staff and even specialists in certain fields, the utility of the impact factor occurs when they want to publish a paper but do not know the best place to publish it. If they wish, many readers from the scientific environment find that the safest method is to publish their work in journals with a high impact factor. But the road from wishing to publish to actually publishing the paper is often very difficult, because in journals that are part of ISI impact factor survey, most often the editorial policy is concentrated on obtaining an impact factor as high as possible. As we shall see later in the present paper, this imposes certain restrictions to the authors, such as the articles they cite in the study they want to publish, or even regarding the subject of the study itself. Because journals with ISI impact factor often have high rates of readership, there is pressure to accept an article to be published, and the quality or scientific importance of a paper are rarely top criteria for accepting a paper for publication.

Researchers and teachers in many countries are evaluated based on the number of ISI articles published, and some countries even grant management research projects to specialists who have published ISI articles. Therefore for these categories of beneficiaries, the ISI rating system is often only mandatory and not one wanted or sought by their own author's initiative.

\footnotetext{
${ }^{5}$ Garfield, E., "Science Citation Index- A New Dimension in Indexing," Science 1664, Vol. 144, No. 3619: 649$6 \mathrm{~S} 4$.
} 
Government agencies, universities and some academic societies are usually the biggest supporters of the ISI rating process and scientific journals. For these beneficiaries, the ISI system is ideal because it establishes a hierarchy in a field where measuring quality is not easy to do.

For decades, those in the scientific community have been struggling to find ways to evaluate the production quality of scientific publishing, ideally with a similar measure. As a result of these endeavors, a new discipline has emerged and developed: bibliometrics. With the advent of the ISI impact factor, bibliometrics experienced a stunning development. The innovation of the approach of impact factor brought the use of a single and simple formula to assess the impact and create hierarchies of these publications.

In Europe, many countries have adopted the ISI impact factor as an indicator of quality, and in Romania as elsewhere, this has impacted the granting of degrees for teaching and research titles. However, European scientific policy is governed by the European Science Foundation which correctly understood the role of the impact factor and has not imposed it as an indicator of quality. In addition, the European Science Foundation has created its own bibliometric database for humanities called the ERIH, where new hierarchies of scientific journals other than those imposed by the Journal Citation Index have appeared.

Adam Davis (2002) ${ }^{6}$ points out several cases of European countries where the ISI impact factor is used as an indicator of quality. German universities frequently determine budget allocation for university departments based on the number of articles published by its members in journals with a high impact factor. In application grants for the Italian Association for Cancer Research, applicants must complete a form to compute the average impact factor ISI journals in which they publish.

Finland is an extreme example; university hospitals here are funded according to the number of points obtained from publication in journals with ISI impact factor. In addition, the impact factor value obtained by the periodical in which the university hospital members have published greatly influences the amount allocated. The impact factor for journals is essentially an indicator of citations and thus should not be used as an indicator of quality. Editors of prestigious scientific journals, many of which ISI quoted, have tried to explain in their editorials the difference between an indicator of the number of citations and indicators of quality. The same idea is shared and supported by many scientific researchers or academics whose work is evaluated qualitatively using this indicator.

Harvey Goldstein and Edward Bergman and Gunther Maier conducted a study in 2010-2011 ${ }^{7}$ to evaluate the importance and reputation of scientific journals, specifically targeting researchers in Europe and the United States. The two researchers gave the scientific community a questionnaire on the two subjects and then processed the data in order to compare it with the ISI impact factor. The results were surprising because, among the fifteen most respected periodicals, seven are not on the ISI index; the most appreciated journal in the ISI hierarchy was found listed in the sixth position of its field.

There are various reasons why a high quality magazine has a low impact factor, or why scientific journals of lower quality achieve a high impact factor. In a similar manner, there are various methods to artificially raise the impact factor of a journal.

\section{Case Study: Scientometric research using Web of Science in the field: Ethics in recovery}

The model developed for this case study was based on a database query of the ISI Web of Science Core Collection focusing primarily on two key words: ethics and medical rehabilitation, searching by

\footnotetext{
${ }^{6}$ Adam, David. “The Counting House,” Nature, 6873 (2002): 726-9.

${ }^{7}$ Harvey Goldstein \& Edward Bergman \& Gunther Maier, 2013. "University mission creep? Comparing EU and US faculty views of university involvement in regional economic development and commercialization," The Annals of Regional Science, Springer; Western Regional Science Association, vol. 50(2), pages 453-477, April.
} 
subject, using Boolean operators to remove unrelated items. Were sought only articles in English Only articles in English were sought after. 85 results were thus obtained. Redefining the research and focusing only on relevant topics in the areas of rehabilitation and ethics resulted 41 results (Fig.1)

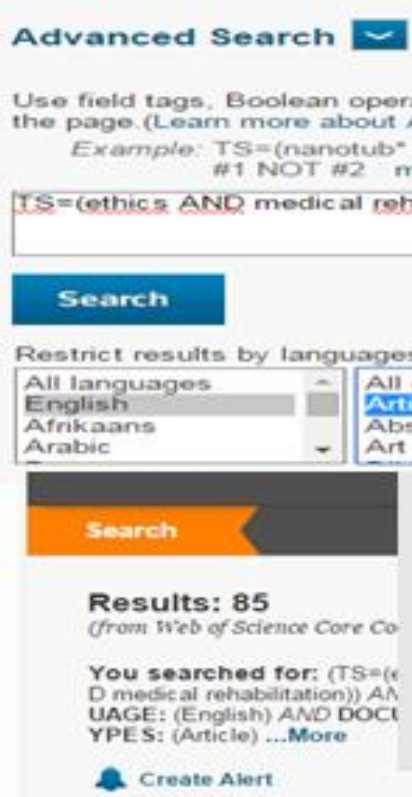

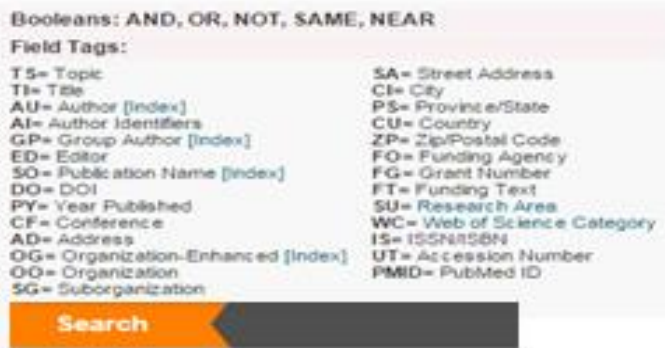

Results: 41

Grom web of sctence Care collection)

You searched for: (TS=)(ethics AN OMGE: al rehabilitation)) AND LANG YPES: (Article) ... More

A create Alert

\section{Document Types}

ARTICLE (41)

PROCEEDINGS PAPER (2)

Fig. 1: Research criteria in Web of Science

The file was saved with all these data as a Bibtex fill the author, world title, source (journal) and abstract were automatically selected and included. (Fig. 2)

\section{田}

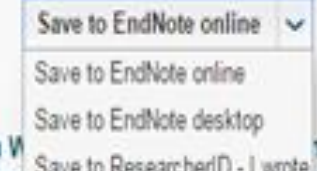

Ethical Perspectives in $V$ Vocabulary for Analyzing

By. Stahl Christian, MacEzx: Save to Cther File Formats

JOURCAL Of BUSINESS ETHICS Volume 120 issue. 2 Pages 237.250 Pudished MAR 2014

View Abstract

2. Honorary Authorship: Frequency and Associated Factors in Physical Medicine and Rehabilitation Research Articles

By. Rajasekaran Sathish Shan Rodrey L P. Fimoif, Jonathan T. ARCHIVES OF PHYSICAL MEDICNE AND REHABILITATION Volume: 95 issue: 3 Pages 418428 Published MAR 2014

View Abstract

Fig. 2: Saving the file as Bibtex

Times Cited: 2

(trour Wed of Stiena core Collection)

\section{三 Analyze Results il Create Citation Report \\ Times Cited: 0 \\ trons Web of Science Core collection)}


For scientometric analysis, the software Sci2 Tools was used. (Fig.3)

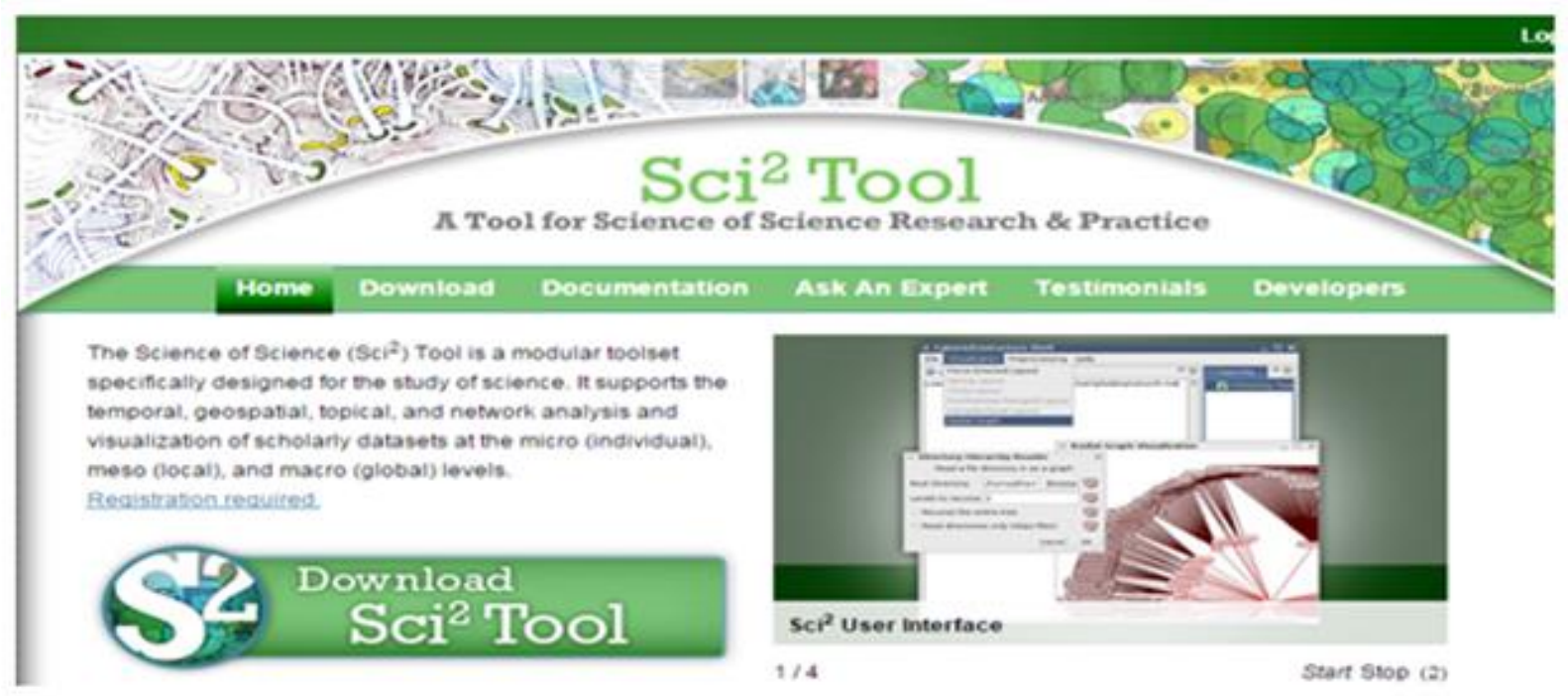

Fig. 3: Image of website software Sci2 Tool

With this software we can generate a tree graph of connections between authors; one particular function can show the closeness or the distance between two nodes (authors or articles), which in turn can generate relevant conclusions on subject studied. (Fig.4)

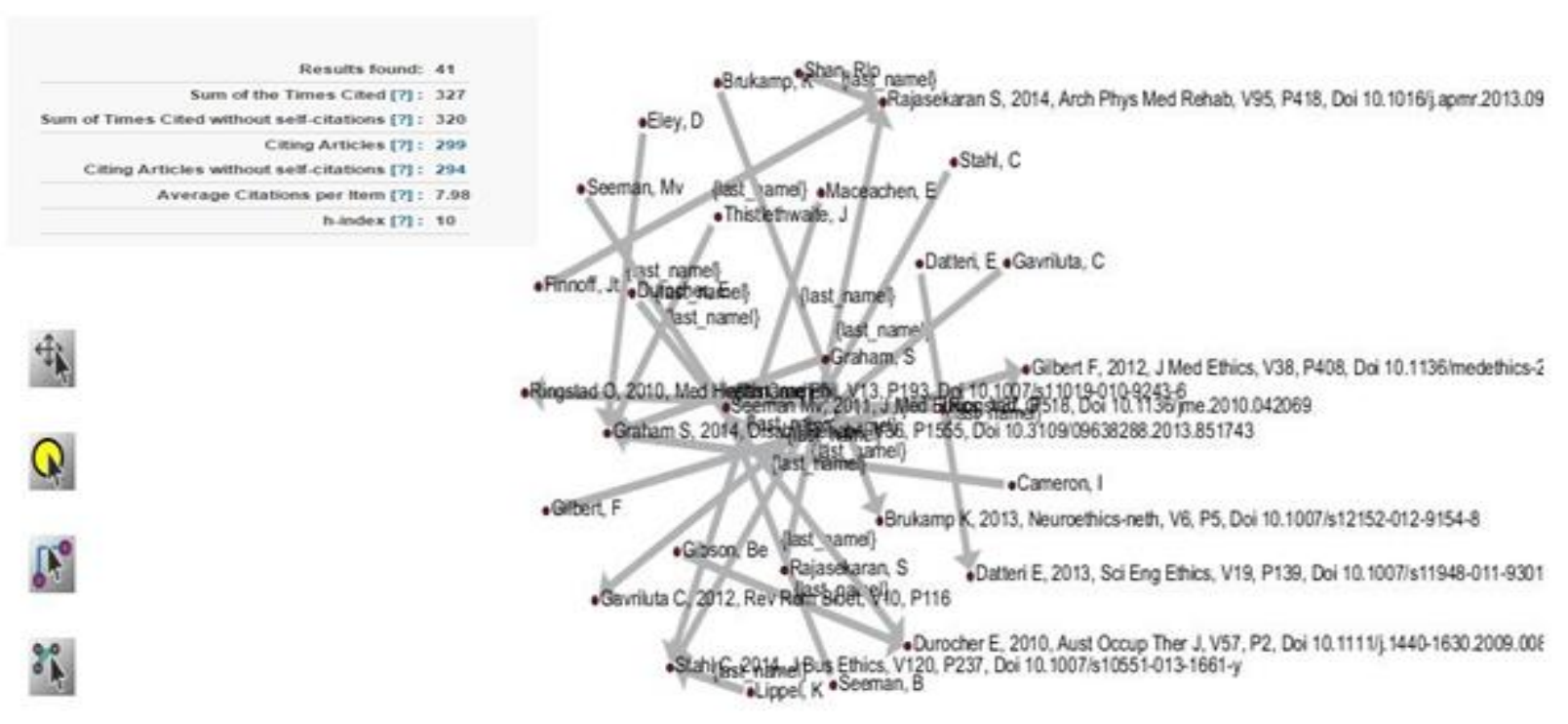

Fig. 4: Authors network analysis

Our analysis generated ten of the most read authors from the fields in question, the top ten topics and the top ten journals publishing in the field of interest. (Fig.5). 


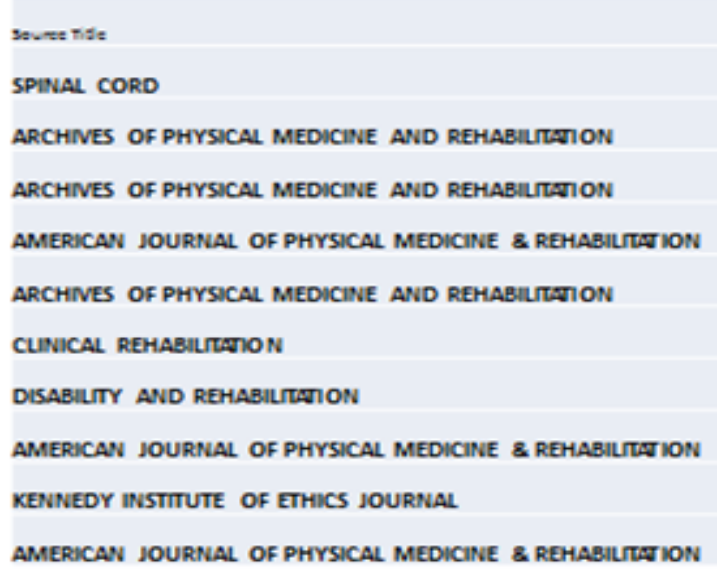

Fig. 5: The top journals in the field

We can summarize the most relevant articles found in the top ten focusing on the aforementioned fields of study:

> The largest response (24\%) was classified as pressures resulting from changes in health care reimbursement. The second most common topic (17\%) involved conflicts among patients, doctors, team members, and families concerning the setting of goals in relation to patient health. The difficulty in assessing decision-making capabilities was third (7\%). Respondents agreed to discussion groups or interdisciplinary services and lectures on self-training materials, like formats for ethical education.

$>$ Exploring ethical considerations and moral conflict inherent in formulating treatment goals and defaulting for patient payment, and provides a framework to help resolve such conflicts. Setting goals is also considered in the broader context of justice equity in the use of healthcare resources.

$>$ Specific difficulties arising in this area of practice are identified here. These relate to communication difficulties with patients who have neurological impairment, competence issues related to patient decision making, problems of consent between patient and professional and the role of the patient's in the rehabilitation process.

$>$ Cultural beliefs affect how health professionals and consumers view health, disease and disability. This discussion focuses on: the therapeutic relevance of cultural beliefs, implications of cultural practices and cultural values for rehabilitation.

$>$ Rehabilitation professionals have become masters of inpatient rehabilitation but are less prepared to facilitate a complete rehabilitation within the framework of outpatient care. Ambulatory Rehabilitation must also consider community reintegration. In the treatment of chronic disability, caretakers and people with disabilities develop interdependence alternating intermittently in a relationship of paternalism and autonomy. Mutual respect, such as that of friends, provides a useful model for this idealized patient-caretaker team.

\section{Conclusions}

The impact factor of a scientific journal has always measured how often certain sources are cited in academic prose; low impact is not equivalent to low quality. If the evaluators of scientific institutions, researchers, academic staff or specialists want to measure the impact that scientific editorial production has in the scientific community, then the ISI impact factor is a suitable instrument. 
However, if the assessor wants to evaluate the quality of a piece, another method of evaluation is needed.

The emergence of the impact factor in academic publications has revolutionized scientific writing, but it has brought numerous prejudices when it became more than a bibliometric indicatos for scientific serial publications, as was initially intended. Today it is also an evaluation tool for scientific institutions and academic researchers.

ISI impact factor, together with bibliometric indicators in the Thomson Scientific database can provide insight into the impact that a periodical has in the scientific world, but not its quality. It should be understood that evaluating the quality of a publication, an institution or a researcher using the ISI impact factor means equating celebrity with quality.

Excessive use of the impact factor has managed to arouse much dislike in nearly every regard. Managers of government agencies and universities love this metric because it presents itself as an objective tool of evaluation. Researchers and academics hate this because they know that impact factor on measures quantity, not production quality of scientific documentation.

The innovation of the approach in this case study is the idea of introducing social network analysis software for scientific research in order to:

Achieve a better understanding of the structure of present scientific data in academic databases

- Facilitate the identification of important items underlying a systemic review of the literature/documentation

- Identify the degree of interaction between relevant scientific papers

- Develop new types of scientific research

\section{References}

Adam, David. "The Counting House," Nature, 6873 (2002): 726-9.

Brodman, Estelle. "Choosing Physiology Journals," Bulletin of the Medical Library Association 32(4) (1944): 479-83, Available online at:

http://www.ncbi.nlm.nih.gov/pmc/articles/PMC194405/pdf/mlab00266-0074.pdf

Cameron, Brian D.. "Trends in the Usage of ISI Bibliometric Data: Uses, Abuses, and Implications," Portal: Libraries and the Academy, 5(1) (2005): 105-25.

European Science Foundation. "Setting Science Agenda for Europe." Accessed may 2013. http://www.esf.org/index.php?eID=tx_nawsecuredl\&u=0\&file=fileadmin/.

Garfield, Eugene. "The Agony and the Ecstasy - the History and the Meaning of the Journal Impact Factor," Chicago ed. International Congress on Peer Review And Biomedical Publication, (2005): 1-20. [accessed may 2013]. Available online at:

http://garfield.library.upenn.edu/papers/jifchicago2005.pdf.

Gilayrevskii, R. S., Chernyi, A. I. , Doctor Eugene Garfield: Scientific-Information Activities, ” Scientific and Technical Information Processing, 36 (3) (2009): 156-9.

Gross P. L. K., Gross E. M., “College Libraries and Chemical Education”, Science 66 (1713): 385-9. Available online database Jstor: http://www.jstor.org/stable/1651803

Salet, Willem and Boer, Rene. "Comparing the Use and Valuation of Journals between U.S. and European Planning Scholars," Journal of Planning Education and Research, 31(95) (2011): 95-7.

Thomson Reuters. "Company History." Accessed may 2013. http://thomsonreuters.com/about/company_history/ 